\title{
PREVALENSI STRES AKADEMIK MAHASISWA
}

\author{
Zamroni \\ zamroni_th@yahoo.com \\ Fakultas Psikologi \\ Universitas Islam Negeri (UIN) Maulana Malik Ibrahim Malang
}

\begin{abstract}
Abstrak - Penelitian ini bertujuan untuk mengetahui dan menggambarkan prevalensi stres akademik mahasiswa di Universitas Islam Negeri (UIN) Maulana Malik Ibrahim Malang. Desain penelitian ini termasuk penelitian deskriptif dengan sampel penelitian sejumlah 390 mahasiswa semester pertama dari 13 jurusan yang berbeda. Instrumen penelitian diadaptasikan dari Educational Stress Scale. Hasil penelitian menunjukkan bahwa prevalensi stres akademik secara keseluruhan mencapai 16,2\% kategori tinggi dan 70,5\% kategori sedang. Selain itu, pervalensi tertinggi pada tiap-tiap jurusan meliputi Jurusan Pendidikan Agama Islam (36,7\%), Jurusan Al-Ahwal al-Syakhsiyah (30\%), Jurusan Fisika (26,6\%), Jurusan Farmasi, $(23,3 \%)$ dan Jurusan Manajemen $(23,3 \%)$. Prevalensi ini berkorelasi dengan jurusan yang dipilih, serta memiliki perbedaan secara signifikan pada masing-masing jurusan. Sebagai saran, perlu pelayanan bimbingan dan konseling di perguruan tinggi dalam mencegah dan mengatasi stres akademik mahasiswa.
\end{abstract}

Keyword: Prevalensi, Stres Akademik, Mahasiswa

PSIKOISLAMIKA. Jurnal Psikologi Islam (JPI) copyright ๔ 2015 Pusat Penelitan dan Layanan Psikologi. Volume 12. Nomor 2, Tahun 2015

\section{PENDAHULUAN}

Jumlah mahasiswa di perguruan tinggi, baik swasta maupun Negeri dari tahun ke tahun terus mengalami peningkatan. Rata-rata peningkatan jumlah mahasiswa pertahun di lingkungan Perguruan Tinggi Keagamaan Islam sebesar 3,4\% $( \pm 13.045)$ sejak tahun 2009-2014 (PDDIKTI, 2016). Universitas Islam Negeri (UIN) Maulana Malik Ibrahim Malang sebagai salah satu pilot project perguruan tinggi Islam di lingkungan Kementerian Agama dalam menjadi contoh atau role model bagi perguruan tinggi Islam lainnya dari tahun ke tahun juga terus mengalami peningkatan jumlah mahasiswa.

Peningkatan jumlah mahasiswa di Universitas Islam Negeri (UIN) Maulana Malik Ibrahim Malang merupakan salah satu gejala dari dampak arus globalisasi dan industrialisasi yang berlangsung dengan sangat cepat di dunia. Arnett (2015) mengatakan bahwa peningkatan minat atau aspirasi mahasiswa untuk belajar di perguruan tinggi terjadi secara merata di berbagai negara maju dan negara berkembang, khususnya di Indonesia meskipun hanya terbatas pada kalangan menengah ke atas. Kompetensi merupakan persyaratan mutlak yang diharapkan dari seorang sarjana agar kelak bisa bersaing dan diterima dalam pasar kerja atau industri. Oleh karenanya mahasiswa berbondong-bondong masuk perguruan tinggi untuk mengembangkan diri mereka.

Peningkatan jumlah mahasiswa ini pada dasarnya bisa menguntungkan Negara dengan asumsi bahwa peningkatan jumlah mahasiswa akan berdampak pada peningkatan sumber daya manusia yang terdidik dan memadai, serta memiliki kualifikasi dan kompetensi profesional yang bisa dibutuhkan dalam persaingan dunia kerja. Namun, harapan ini pada kenyataannya belum bisa terwujud dengan baik. Kepala Badan Pusat Statistik mengatakan bahwa pada Februari tahun 2016 jumlah pangangguran terbuka mengalami penurunan dari tahun 2015 sebesar $0,31 \%$, akan tetapi pengangguran terbuka 
yang berlatar belakang sarjana justru mengalami peningkatan dari $5,34 \%$ menjadi $6,22 \%$ (Tempo, 2016). Kondisi ini menunjukkan bahwa perguruan tinggi belum berhasil dalam menyiapkan calon sarjana dalam menghadapi persaingan dunia kerja.

Salah satu masalah yang dihadapi perguruan tinggi adalah stres akademik yang dialami oleh mahasiswa. Beberapa penelitian menunjukkan bahwa prevalensi stres akademik di kalangan mahasiswa cukup tinggi. Prevalensi stres akademik mahasiswa kedokteran di Taibah University Al Munawarah Kongdom of Arabia Saudi mencapai 40,7\% (Habeeb, 2010), di Nicolaus Copernicus University in Poland mencapai 23\% (Rosiek, et. al, 2012), di Medical Colleges in Kerala (India) mencapai 69,7\% (Sivan \& Rangasubhe, 2013), di Casablanca Medical School (Afrika) mencapai 52,7\% (Loubir, et. al, 2014), di Universiti Putra Malaysia mencapai 49,3\% (Phang, et. al, 2015), dan di Bayero University Kano Medical School (Nigeria) mencapai 59,8\% (Asani et. al, 2016).

Prevalensi yang tinggi di kalangan mahasiswa kedokteran dari beberapa negara tersebut juga terjadi di Indonesia. Prevalensi stres akademik mahasiswa Institut Pertanian Bogor yang tinggal di asrama mencapai 95,4\% (Hernawati, 2006), mahasiswa kedokteran Universitas Sam Ratulangi mencapai 48,4\% (Talumewo, dkk., 2014), mahasiswa D-III keperawatan di DKI Jakarta mencapai 83,5\% (Rakhmawati, dkk., 2014), mahasiswa D-III kebidanan Stikes PKU Muhammadiyah Surakarta mencapai 90,6\% (Fatmawai \& Sari, 2015), dan mahasiswa Fakultas Keguruan dan Ilmu Pendidikan Universitas Kanjuruhan Malang mencapai 90,9\% (Bariyyah \& Latifah, 2015).

Berbagai hasil penelitian tersebut menunjukkan bukti empirik bahwa stres akademik yang dialami mahasiswa merupakan fenomena global. Masalah ini tidak hanya terjadi di Indonesia, namun terjadi di berbagai perguruan tinggi di dunia, serta tidak hanya terbatas pada kalangan mahasiswa Jurusan Kedokteran, namun juga terjadi pada mahasiswa Jurusan Pertanian (Hernawati, 2006), Keperawatan (Rakhmawati, dkk., 2014), Kebidanan (Fatmawai \& Sari, 2015), dan Fakultas Keguruan dan Ilmu Pendidikan (Bariyyah \& Latifah, 2015). Oleh karenanya, penelitian ini bertujuan untuk menggali dan mendeskripsikan tingkat prevalensi stres akademik di kalangan mahasiswa semester pertama dari berbagai jurusan yang ada di lingkungan Universitas Islam Negeri (UIN) Maulana Malik Ibrahim Malang.
Penelitian ini perlu dilakukan dikarenakan prevalensi stres akademik dari tahun ke tahun menunjukkan angka yang cukup tinggi. Peningkatan minat (aspirasi) mahasiswa untuk melanjutkan studi di perguruan tinggi juga terus bertambah. Bimbingan dan konseling sebagai salah satu bidang integral pendidikan dalam mencapai pendidikan yang ideal, bermutu, dan berkualitas tidak ditemukan di kebanyakan perguruan tinggi di Indonesia. Absensi konselor (salah satu pendidik profesional) dari perguruan tinggi berdampak pada pengabaian masalah stres akademik di kalangan mahasiswa (Zamroni, dkk., 2016). Kondisi ini menyebabkan pembinaan dan pengembangan kompetensi pengembangan diri pada diri mahasiswa tidak terwujud. Kompetensi pengembangan diri yang lemah pada diri mahasiswa berdampak pada kerentanan mereka terhadap gangguan stres ketika menghadapi kesulitan dalam bidang akademik maupun pekerjaan.

Seorang psikolog, Arnett (2015) mengatakan bahwa anak muda usia 18-25 tahun, termasuk juga mahasiswa berada pada suatu tahapan perkembangan emerging adulthood. Tahapan ini relatif baru karena mahasiswa berada pada suatu posisi antara masa remaja akhir dan dewasa awal. Tahapan ini dicirikan atas lima hal, yaitu 1) masa eksplorasi identias karier dan pasangan, 2) masa ketidakstabilan dalam eksplorasi identitas, 3) masa fokus pada kemandirian dan kebebasan diri, 4) masa antara remaja dan dewasa, dan 5) masa optimisme terhadap harapan dan cita-cita. Kelima ciri ini menunjukkan bahwa mahasiswa membutuhkan perhatian khusus dari konselor, terutama dalam proses studi di perguruan tinggi, agar tidak mudah mengalami stres.

Karakteristik perkembangan ini sesuai dengan salah satu kompetensi kemandirian yang harus dikuasai mahasiswa, yaitu kompetensi pengembangan diri. Kompetensi ini meliputi 1) mahasiswa mampu mempelajari berbagai peluang pekerjaan, 2) mahasiswa memiliki keyakinan tentang keunikan diri sebagai aset yang harus dikembangkan secara harmonis dalam kehidupan, dan 3) mahasiswa mampu mengembangkan aset diri secara harmonis dalam kehidupan (Depdiknas, 2008). Kompetensi ini pada dasarnya sangat mungkin dikembangkan di perguruan tinggi melalui bantuan konselor yang bekerjasama dengan pendidik lainnya. Pengabaian terhadap kebutuhan ini akan berdampak pada kerentanan mahasiswa terhadap gangguan stres akademik ketika belajar di kampus, dan bahkan setelah lulus dari perguruan tinggi. 
Definisi tentang stres sudah banyak dijelaskan oleh para peneliti, akan tetapi tidak satupun yang bisa memberikan definisi secara memuaskan (Lazarus \& Folkman, 1984). Mason (dalam Aldwin, 2007) menyimpulkan definisi stres yang seringkali digunakan, yaitu 1) stres digunakan untuk merujuk pada kondisi internal (internal state) individu yang terkadang disebut strain, 2) stres digunakan untuk merujuk pada peristiwa eksternal (external events) yang terkadang disebut stressor, dan 3) stres digunakan untuk merujuk pada pengalaman (experience) yang muncul dari suatu transaksi antara individu dengan lingkungannya. Definisi stres yang pertama (strain) dan kedua (stressor) merupakan definisi stres stimulus dan respon sebagaimanà dijelaskan Lazarus \& Folkman (1984). Definisi ini muncul dari beberapa tokoh di antaranya Walter Cannon (1932), Hans Selye (1936), dan Harold G. Wolf (1953) yang lebih fokus pada stimulus dan respon stres tanpa mempedulikan faktor-faktor personal individu yang sangat berperan dalam mempersepsikan sebuah peristiwa stres (Lazarus \& Folkman, 1984).

Lazarus \& Folkman (1984) memperhatikan faktor-faktor personal individu yang dinilai sangat penting dan berpengaruh dalam mempersepsikan peristiwa stres (stressor). Peristiwa yang sama bisa saja dipersepsikan secara berbeda oleh dua orang yang berbeda, baik itu secara positif maupun negatif. Proses penilaian ini disebut sebagai appraisal yang terdiri atas dua tahap, yaitu primary appraisal yang berkaitan dengan individu mempertanyaan bagaimana keadaan dirinya berkenaan dengan situasi stres, dan secondary appraisal yang berkaitan dengan sumber apa yang dimiliki dan bisa digunakan untuk mengatasi situasi stres tersebut. Selain itu, bentukbentuk tindakan yang dilakukan individu dalam mengatasi stres disebut sebagai coping strategy. Kompleksitas dalam memahami dan mendefinisikan stres, maka Lazarus \& Folkman (1984) lebih suka menyebutnya sebagai rubrik stres.

Definisi Lazarus \& Folkman (1984) mengenai stres dikenal dengan psychological stress atau disebut teori transaksional. Stres psikologis adalah suatu kaitan antara individu dengan lingkungan yang dinilai oleh individu melebihi sumber daya (resources) yang dimiliki dan membahayakan kesejahteraan dirinya. Stres yang dialami individu pada dasarnya merupakan hasil transaksi antara dirinya dengan lingkungan yang dihadapinya. Definisi ini memandang bahwa individu terlibat secara aktif dalam proses berlangsungnya stres yang terjadi dalam diri individu.

Sumber stres yang paling utama di kalangan mahasiswa sebagaimana diketahui dari beberapa hasil penelitian adalah kegiatan dan tugas-tugas akademik (Agolla \& Ongori, 2009; Christyanti, dkk., 2010; Evangelia \& Spiridon, 2011). Oleh karenanya, beberapa peneliti menyebut stres dalam konteks akademik ini dengan istilah stres akademik. Selain itu, Sun, et. al, (2011) menyebut stres akademik ini dengan istilah educational stress yang terdiri atas lima aspek, yaitu tekanan pelajaran (pressure from study), beban tugas (workload), kekhawatiran terhadap nilai (worry about grade), harapan diri (self-expectation), dan kesedihan (despodency). Berdasarkan berbagai penjelasan tersebut, maka definisi stres akademik adalah kondisi yang dialami dan dirasa membahayakan diri mahasiswa sebagai hasil dari proses transaksi antara dirinya dengan lingkungan akademik di perguruan tinggi.

\section{METODE}

Desain penelitian yang digunakan termasuk dalam kategori penelitian deskriptif. Penelitian ini bertujuan untuk menggambarkan dan menjelaskan tingkat prevalensi stres akademik mahasiswa di tiap-tiap jurusan. Selain itu, sebagai analisis tambahan, penelitian ini juga melihat hubungan dan perbedaan stres akademik pada tiap-tiap jurusan. Populasi penelitian ini adalah seluruh mahasiswa semester pertama Universitas Islam Negeri (UIN) Maulana Malik Ibrahim Malang. Sampel penelitian sejumlah 390 mahasiswa yang diperoleh melalui teknik sampling kuota (quota sampling). Sampel penelitian tersebut terdiri atas 30 mahasiswa dari tiap-tiap jurusan di antaranya Jurusan Akuntansi, Manajemen, Perbankan, Bahasa dan Sastra Inggris, Pendidikan Agama Islam, Pendidikan Bahasa Arab, Pendidikan Guru Madrasah Ibtidaiyah, Pendidikan Dokter, Fisika, Kimia, Farmasi, Al-Ahwal alSyakhsiyah, dan Hukum Bisnis Syari'ah. Instrumen penelitian diadaptasikan dari Educational Stress Scale (Sun, et. al, 2011) yang awalnya berjumlah 15 dan setelah melalui uji coba diperoleh aitem berjumlah 10 aitem dengan validitas aitem $\geq 0,3$ yang terentang dari $0,324-0,540$, dan reliabilitas sebesar 0,780. Teknik analisis data yang digunakan adalah statistik deskriptif, tabulasi silang, dan Oneway Anova.

\section{HASIL}

Stres akademik yang dialami mahasiswa Universitas Islam Negeri (UIN) Maulana Malik Ibrahim 
Malang menunjukkan angka yang cukup signifikan. Berdasarkan hasil analisis pada $\mathbf{3 9 0}$ mahasiswa semester pertama yang tersebar di 13 jurusan (Tabel 1) diketahui bahwa secara keseluruhan prevalensi stres akademik mahasiswa mencapai $16,2 \%$ kategori tinggi, $70,5 \%$ kategori sedang, dan $13,3 \%$ kategori rendah.

Tabel 1: Prevalensi Stres Akademik Mahasiswa

\begin{tabular}{lccccccc}
\hline \multirow{2}{*}{ Jurusan } & \multicolumn{7}{c}{ Stres Akademik Mahasiswa } \\
\cline { 2 - 8 } & Rendah & $\%$ & Sedang & $\%$ & Tinggi & $\%$ & Total \\
\hline Akuntansi & 4 & $13,3 \%$ & 24 & $80 \%$ & 2 & $6,7 \%$ & 30 \\
\hline Manajemen & 3 & $10 \%$ & 20 & $66,7 \%$ & 7 & $23,3 \%$ & 30 \\
\hline Perbankan (S1) & 4 & $13,3 \%$ & 22 & $73.4 \%$ & 4 & $13,3 \%$ & 30 \\
\hline Bahasa dan Sastra Inggris & 4 & $13,3 \%$ & 24 & $80 \%$ & 2 & $6,7 \%$ & 30 \\
\hline Pendidikan Agama Islam & 3 & $10 \%$ & 16 & $53,3 \%$ & 11 & $36,7 \%$ & 30 \\
\hline Pendidikan Bahasa Arab & 8 & $26,7 \%$ & 21 & $70 \%$ & 1 & $3,3 \%$ & 30 \\
\hline Pendidikan Guru MI & 4 & $13,3 \%$ & 23 & $76,7 \%$ & 3 & $10 \%$ & 30 \\
\hline Pendidikan Dokter & 4 & $13,3 \%$ & 25 & $83,4 \%$ & 1 & $3,3 \%$ & 30 \\
\hline Fisika & 0 & $0 \%$ & 22 & $73,4 \%$ & 8 & $26,6 \%$ & 30 \\
\hline Kimia & 4 & $13,3 \%$ & 21 & $70 \%$ & 5 & $16,7 \%$ & 30 \\
\hline Farmasi & 3 & $10 \%$ & 20 & $66,7 \%$ & 7 & $23,3 \%$ & 30 \\
\hline Al-Ahwal al-Syakhsiyah & 4 & $13,3 \%$ & 17 & $56,7 \%$ & 9 & $30 \%$ & 30 \\
\hline Hukum Bisnis Syari'ah & 7 & $23,3 \%$ & 20 & $66,7 \%$ & 3 & $10 \%$ & 30 \\
\hline \multicolumn{1}{c}{ Total } & 52 & $13,3 \%$ & 275 & $70,5 \%$ & 63 & $16,2 \%$ & 390 \\
\hline
\end{tabular}

Prevalensi stres akademik yang termasuk dalam kategori tinggi didominasi oleh mahasiswa Jurusan Pendidikan Agama Islam (36,7\%), Jurusan Al-Ahwal al-Syakhsiyah (30\%), Jurusan Fisika (26,6\%), Jurusan Farmasi, $(23,3 \%)$ dan Jurusan Manajemen $(23,3 \%)$. Selain itu, prevalensi stres akademik yang termasuk dalam kategori rendah didominasi oleh mahasiswa Jurusan Pendidikan Bahasa Arab $(26,7 \%)$ dan Jurusan Hukum Bisnis Syari'ah (23,3\%). Adapun prevalensi stres akademik yang termasuk dalam kategori sedang didominasi oleh mahasiswa Jurusan Pendidikan Dokter $(83,4 \%)$, Jurusan Akuntansi $(80 \%)$ dan Jurusan Bahasa dan Sastra Inggris (80\%).

Prevalensi stres akademik mahasiswa tersebut berhubungan dengan latar belakang jurusan pendidikan yang ditempuh. Berdasarkan hasil analisis tabulasi silang (Tabel 1 dan Tabel 2) diketahui bahwa terdapat hubungan antara jenis jurusan dengan stres akademik mahasiswa. Hasil uji korelasi melalui analisis Chi-Square diperoleh nilai $r=41,306(p=$ $0,015<0,05$ ) yang menyatakan bahwa terdapat hubungan antara latar belakang jurusan dengan stres akademik mahasiswa. Selain itu, nilai Phi, Cramer's V, dan Contingency Coefficient (Tabel 2) menunjukkan korelasi yang cukup signifikan antara jurusan dengan stres akademik mahasiswa.
Tabel 2. Nilai Korelasi Tabulasi Silang

\begin{tabular}{lcc}
\hline \multicolumn{1}{r}{ Jenis Nilai } & Skor & $\mathrm{P}\left(\right.$ sign.) ${ }^{*}$ \\
\hline Phi & 0,325 & 0,015 \\
\hline Cramer's V & 0,230 & 0,015 \\
\hline Contingency & 0,309 & 0,015 \\
Coefficient & &
\end{tabular}

${ }^{*} p$ (sign. $)<0,05$

Ketiga nilai $P h i=0,325$, Cramer's $V=0,230$, dan Contingency Coefficient $=0,309$ dengan nilai $p=$ $0,015<0,05$ menyatakan bahwa jurusan berkorelasi dengan stres akademik mahasiswa. Ketiga nilai tersebut menunjukkan hubungan yang signifikan meskipun masih tergolong cukup dan belum terlalu terlalu kuat. Semakin mendekati 1,000, maka nilai korelasi yang dihasilkan oleh tiap-tiap kategori tersebut akan semakin kuat dalam memprediksikan hubungan.

Prevalensi stres akademik mahasiswa tersebut dilihat dari aspek perbedaan jurusan menunjukkan bahwa sebagian jurusan memiliki perbedaan secara signifikan, sedangkan sebagian lainnya tidak memiliki perbedaan (Tabel 3). Hasil uji beda melalui analisis statistik Oneway Anova diperoleh nilai $F=3,018$ ( $p$ $=0,000<0,05$ ) yang menyatakan bahwa terdapat perbedaan tingkat stres akademik mahasiswa di antara tiap-tiap jurusan. 
Tabel 3. Perbedaan Stres Akademik Mahasiswa

\begin{tabular}{|c|c|c|c|c|c|c|c|c|c|c|c|c|c|}
\hline \multirow{2}{*}{ Jurusan } & \multicolumn{13}{|c|}{ Jurusan } \\
\hline & AKT & MNJ & PBK & BSI & PAI & PBA & PGMI & PDR & FSK & KMA & FRM & AS & HBS \\
\hline AKT & - & & & & & & & & & & & & \\
\hline MNJ & , 166 & - & & & & & & & & & & & \\
\hline PBK & $-1,76$ & $-1,93$ & - & & & & & & & & & & \\
\hline BSI &,- 866 & $-1,03$ & ,900 & - & & & & & & & & & \\
\hline PAI & 2,26 & 2,10 & $4,03^{*}$ & $3,13^{*}$ & - & & & & & & & & \\
\hline PBA & $-3,03^{*}$ & $-3,20^{*}$ & $-1,26$ & $-2,16$ & $-5,30^{* *}$ & - & & & & & & & \\
\hline PGMI & $-1,26$ & $-1,43$ &, 500 &,- 400 & $-3,53^{*}$ & 1,76 & - & & & & & & \\
\hline PDR & $-1,83$ & $-2,00$ &,- 066 &,- 966 & $-4,10^{*}$ & 1,20 &,- 566 & - & & & & & \\
\hline FSK & 2,33 & 2.16 & $4,10^{*}$ & $3,20^{*}$ &, 066 & $5,36^{\text {** }}$ & $3,60^{*}$ & $4,16^{*}$ & - & & & & \\
\hline KMA & .366 & 200 & 2,13 & 1,23 & $-1,90$ & $3,40^{*}$ & 1,63 & 2,20 & $-1,96$ & - & & & \\
\hline FRM & 1,10 & ,933 & $2,86^{*}$ & 1,96 & $-1,16$ & $4,13^{*}$ & 2,36 & $2,93^{*}$ & $-1,23$ & 7,33 & - & & \\
\hline AS & ,833 & ,666 & 2,60 & 1,70 & $-1,43$ & $3,86^{*}$ & 2,10 & 2,66 & $-1,50$ & ,466 &,- 266 & - & \\
\hline HBS & $-1,66$ & $-1,83$ & , 100 &,- 800 & $-3,93$ & 1,36 &,- 400 & , 166 & $-4,00^{*}$ & $-2,03$ & $-2,76$ & $-2,50$ & - \\
\hline
\end{tabular}

AKT = Akuntansi, $M N J=$ Manajemen, $\mathrm{PBK}=$ Perbankan, $\mathrm{BSI}=$ Bahasa \& Sastra Inggris, PAI = Pendidikan Agama Islam, PBA = Pendidikan Bahasa Arab, PGMI = Pendidikan Guru MI, PDR = Pendidikan Dokter, FSK $=$ Fisika, $\mathrm{KMA}=$ Kimia, FRM = Farmasi, AS = Al-Ahwal al-Syakhsiyah, dan HBS = Hukum Bisnis Syari'ah.

Berdasarkan Tabel 3 tersebut diketahui bahwa mahasiswa Jurusan Pendidikaṇ Agama Islam, Jurusan Fisika, Jurusan Farmasi, Jurusan Manajemen, dan Jurusan Akuntansi memiliki perbedaan rerata skor stres akademik yang lebih tinggi dibandingkan jurusan lainnya. Perbedaan tersebut meliputi:

1) Stres akademik mahasiswa Jurusan Pendidikan Agama Islam lebih tinggi daripada mahasiswa Jurusan Perbankan $(M=4,03, p=0,05)$, Jurusan Bahasa dan Sastra Inggris $(M=3,13, p=0,05)$, Jurusan Pendidikan Bahasa Arab $(M=5,30, p$ $=0,001)$, Jurusan Pendidikan Guru Madrasah Ibtidaiyah $(M=3,53, p=0,05)$, dan Jurusan Pendidikan Dokter $(M=4,10, p=0,05)$.

2) Stres akademik mahasiswa Jurusan Al-Ahwal al-Syakhsiyah lebih tinggi daripada mahasiswa Jurusan Pendidikan Bahasa Arab $(M=3,86, p$ $=0,05)$.

3) Stres akademik mahasiswa Jurusan Fisika lebih tinggi daripada mahasiswa Jurusan Perbankan $(M=4,10, p=0,05)$, Jurusan Bahasa dan Sastra Inggris $(M=3,20, P=0,05)$, Jurusan Pendidikan Bahasa Arab $(M=5,36, p=0,001)$, Jurusan Pendidikan Guru Madrasah Ibtidaiyah $(M=3,60$, $p=0,05)$, Jurusan Pendidikan Kedokteran ( $M$ $=4,16, p=0,05)$, dan Jurusan Hukum Bisnis Syari'ah $(M=4,00, p=0,05)$.

4) Stres akademik mahasiswa Jurusan Farmasi lebih tinggi daripada mahasiswa Jurusan Perbankan $(M=2,86, p=0,05)$, Jurusan Pendidikan Bahasa Arab $(M=4,13, p=0,05)$, dan Jurusan Pendidikan Kedokteran $(M=2,93, p=0,05)$.
5) Stres akademik mahasiswa Jurusan Manajemen lebih tinggi daripada mahasiswa Jurusan Pendidikan Bahasa Arab ( $M=3,20, p=0,05)$.

6) Stres akademik mahasiswa Jurusan Akuntansi lebih tinggi daripada mahasiswa Jurusan Pendidikan Bahasa Arab $(M=3,03, p=0,05)$.

7) Stres akademik mahasiswa Jurusan Kimia lebih tinggi daripada mahasiswa Jurusan Pendidikan Bahasa Arab $(M=3,40, p=0,05)$.

\section{DISKUSI}

Prevalensi stres akademik mahasiswa semester pertama di Universitas Islam Negeri (UIN) Maulana Malik Ibrahim Malang menunjukkan angka yang cukup signifikan. Secara keseluruhan dari jumlah sampel 390 mahasiswa diketahui 16,2\% termasuk dalam kategori tinggi, 70,5\% termasuk dalam kategori sedang, dan hanya $13,3 \%$ yang termasuk kategori rendah. Hasil penelitian ini sejalan dengan berbagai hasil penelitian terdahulu tentang stres akademik mahasiswa. Prevalensi stres akademik mahasiswa merupakan fenomena global yang terjadi secara merata di berbagai perguruan tinggi di dunia (Zamroni, dkk., 2016).

Selain itu, prevalensi stres akademik mahasiswa yang termasuk dalam kategori tinggi didominasi oleh Jurusan Pendidikan Agama Islam $(36,7 \%)$, Jurusan Al-Ahwal al-Syakhsiyah (30\%), Jurusan Fisika (26,6\%), Jurusan Farmasi, $(23,3 \%)$ dan Jurusan Manajemen $(23,3 \%)$, sedangkan prevalensi stres akademik yang termasuk dalam kategori sedang didominasi oleh mahasiswa Jurusan Pendidikan Dokter $(83,4 \%)$, 
Jurusan Akuntansi (80\%) dan Jurusan Bahasa dan Sastra Inggris (80\%), serta prevalensi stres akademik yang termasuk dalam kategori rendah didominasi oleh mahasiswa Jurusan Pendidikan Bahasa Arab $(26,7 \%)$ dan Jurusan Hukum Bisnis Syari'ah (23,3\%). Hal ini menunjukkan bahwa stres akademik tidak hanya dialami oleh mahasiswa kedokteran saja (Habeeb, 2010; Rosiek, et. al, 2012; Talumewo, dkk. 2013; Loubir, et. al, 2014; Phang, et. al, 2015; dan Asani et. al, 2016;), namun terjadi secara umum pada beberapa jurusan lainnya (Hernawati, 2006; Rakhmawati, dkk., 2014; Fatmawai \& Sari, 2015; dan Bariyyah \& Latifah, 2015).

Jurusan tertentu di Universitas Islam Negeri (UIN) Maulana Malik Ibrahim Malang memiliki hubungan dengan tingkat stres akademik yang dialami oleh mahasiswa. Berdasarkan hasil uji tabulasi silang diketahui bahwa jenis jurusan berkorelasi dengan stres akademik mahasiswa, meskipun hubungan ini sifatnya tidak begitu kuat. 1) Mahasiswa Jurusan Pendidikan Agama Islam memiliki rata-rata stres akademik yang lebih tinggi dibandingkan mahasiswa Jurusan Perbankan, Jurusan Bahasa dan Sastra Inggris, Jurusan Pendidikan Bahasa Arab, Jurusan Pendidikan Guru Madrasah Ibtidaiyah, dan Jurusan Pendidikan Dokter. 2) Mahasiswa Jurusan Fisika memiliki rata-rata stres akademik yang lebih tinggi

\section{DAFTAR PUSTAKA}

Agolla, J. E. dan Ongori, H. (2009). An assessment of academic stress among undergraduate students: the case of University of Botswana. Educational Research and Review. 4(2), hlm. 063-070.

Aldwin, C. M. (2007). Stress, coping, and development: an integrative perspective (second edition). New York: The Guilford Press.

Arnett, J. J. (2015). The cultural psychology of emerging adulthood. Dalam D. H. Barlow, K. N. Ochsner, M. Kosslyn, D. Reisberg, E. M. Altmaier, dan J. C. Hansen (Eds.), The Oxford Handbook of Human Development and Culture (hlm. 487-501). London: Oxford University Press.

Asani, M. O., Farouk, Z., dan Gambo, S. (2016). Prevalence of perceived stress among clinical students of Bayero University Medical School. Nigerian Journal of Basic and Clinical Sciences, 13(1), hlm. 55-58. dibandingkan mahasiswa Jurusan Perbankan, Jurusan Bahasa dan Sastra Inggris, Jurusan Pendidikan Bahasa Arab, Jurusan Pendidikan Guru Madrasah Ibtidaiyah, Jurusan Pendidikan Kedokteran, dan Jurusan Hukum Bisnis Syari'ah. 3) Mahasiswa Jurusan Farmasi memiliki rata-rata stres akademik yang lebih tinggi dibandingkan mahasiswa Jurusan Perbankan, Jurusan Pendidikan Bahasa Arab, dan Jurusan Pendidikan Kedokteran. 4) Mahasiswa Jurusan Al-Ahwal al-Syakhsiyah, Jurusan Manajemen, Jurusan Akuntansi, dan Jurusan Kimia memiliki ratarata stres akademik yang lebih tinggi dibandingkan mahasiswa Pendidikan Bahasa Arab.

\section{KESIMPULAN}

Prevalensi stres akademik di kalangan mahasiswa dari tahun ke tahun menunjukkan angka yang cukup tinggi. Hal ini perlu diperhatikan oleh pengelola pendidikan tinggi karena berpotensi menganggu kesejahteraan psikologis mahasiswa. Pengelola pendidikan tinggi hendaknya memperhatikan kebutuhan pengembangan psikologis, terutama kesejahteraan psikologis mahasiswa melalui layanan bimbingan dan konseling. Oleh karenanya, layanan bimbingan dan konseling di perguruan tinggi perlu diwujudkan dalam mencegah dan mengurangi bahaya stres akademik di kalangan mahasiswa.

Bariyyah, K. dan Latifah, L. (2015). Tingkat stres akademik mahasiswa Fakultas Keguruan dan Ilmu Pendidikan Universitas Kanjuruhan Malang. Dalam Maria Helena Suprapto (Ed.), Proceedings Konferensi Nasional "Mempersiapkan Kebangkitan Generasi Emas Indonesia 2045 Melalui Revolusi Mental Anak Bangsa (hlm. 270-284). Surabaya: Universitas Pelita Harapan Surabaya.

Christyanti, D., Mustami'ah, D. dan Sulistiani, W. (2010). Hubungan antara penyesuaian diri terhadap tuntutan akademik dengan kecenderungan stres pada mahasiswa fakultas kedokteran Universitas Hang Tuah Surabaya. Insan. 12(3), hlm. 153-159.

Depdiknas. (2008). Penataan pendidikan profesional konselor dan layanan bimbingan dan konseling dalam jalur pendidikan formal. Depdiknas: Jakarta.

Evangelia, K. dan Spiridon, K. (2011). Stages of change, self-efficacy and stress management perceptions in first year undergraduate students. International Journal of Psychology 
and Behavioral Sciences, 1(1), hlm. 24-32.

Fatmawati, V. dan Sari, T. P. (2015). Hubungan antara tingkat stres dengan kesiapan dalam menghadapi karya tulis ilmiah. Profesi, 12(2), hlm. 41-45.

Habeeb, K. A. (2010). Prevalence of stressors among female medical students Taibah University. Journal of Taibah University Medical Sciences, 5(2), hlm. 110-119.

Hernawati, N. (2006). Tingkat stres dan strategi koping menghadapi stres pada mahasiswa tingkat persiapan bersama tahun akademik 2005/2006. Jurnal Ilmu Pertanian Indonesia, 11(2), hlm. 43-49.

Lazarus, R. S. dan Folkman, S. (1984). Stress, appraisal, and coping. New York: Springer Publishing Company.

Loubir, D. B., Serhier, Z., Diouny, S., Battas, O., Agoub, M., dan Othmani, M. B. (2014). Prevalence of stress in Casablanca medical students: a cross-sectional study. Pan African Medical Journal, 19(149), hlm. 1-10.

PDDIKTI (2016). Rekap Jumlah Mahasiswa. Diakses tanggal 20 November 2016 http: / forlap. ristekdikti.go.id/mahasiswa/homerekap/N zJCQTcxNkYtMjdFMCOORUMOLUlyNOUtQjlzQ TQOMjNBNOZC/0.

Phang, C. K., Sherina, M. S., Zubaidah, J. O., Noor Jan, K. O. N., Firdaus, M., Siti Irma, F. I., dan Normala, I. (2015). Prevalence of psychological stress among undergraduate students attending a health programme in a Malaysian University. Pertanika Journal Science \& Technology, 23(1), hlm. 29-35.

Rakhmawati, I., Farida, P., dan Nurhalimah. (2014). Sumber stres akademik dan pengaruhnya terhadap tingkat stres mahasiswa keperawatan
DKI Jakarta. Jurnal Keprawatan, 2(3), hlm. 72-84.

Rosiek, A., Kryszewska, A. R., Leksowski, L., dan Leksowski, K. (2012). Chronic stress and suicidal thinking among medical students. International Journal of Environmental Research and Public Health, 13(212), hlm. 1-16.

Sivan, S. dan Rangasubhe, P. (2013). Prevalence of stress and its associated factors. Journal of Evolution of Medical and Dental Sciences, 2(48), hlm. 9386-9394.

Sun, J., Dunne, M. P., Hou, X., dan Xu, A. (2011). Educational stress scale for adolescents: development, validity, and reliability with Chinese students. Journal of Psychoeducational Assessment, 29(6), hlm. 534-546.

Talumewo, V. R., Pangemanan, D. H. C., dan Marunduh, S. R. (2014). Stres terhadap daya tahan belajar pada mahasiswa angkatan 2013 Fakultas Kedokteran Universitas Sam Ratulangi. Jurnal e-Biomedik, 2(1), hlm. 1-5.

Tempo. (2016). BPS: Pengangguran Terbuka di Indonesia Capai 7,02 Juta Orang. Diakses tanggal 20 November 2016. https://m.tempo.co/read/ news/2016/05/04/173768481/bps-pengangguranterbuka-di-indonesia-capai-7-02-juta-orang.

Zamroni, Hidayah, N., Ramli, M., dan Hambali, IM. (2016). Revitalization of the role and function of guidance and counseling in college to improve student's academic hardiness. Dalam Suwarjo, D. M. Handarini, T. H. Dahlan, dan Y. K. S. Pranoto (Eds.), Prooceeding 1st Semarang State University International Conference on Counseling and Educational Psychology "Developing and Inovation on Helping Profession for Better Life" (hlm. 96-101). Semarang: Program Studi Bimbingan dan Konseling Universitas Negeri Semarang. 